\title{
Analytical Model and Investigation of a Four-Switch Space-Vector Modulated Hybrid Power Filter with Six-Fold Switching Symmetry
}

\author{
J. Klima ${ }^{\#}$, J. Tlusty ${ }^{*}$, J. Skramlik ${ }^{+}$and V. Valouch ${ }^{+}$ \\ "Department of Electrical Engineering and Automation \\ Technical Faculty of CZU in Prague \\ 16627 Prague 6, Czech Republic \\ e-mail: klima@tf.czu.cz \\ *Department of Power Engineering \\ Faculty of Electrical Engineering, CTU \\ 16627 Prague 6, Czech Republic \\ e-mail: tlusty@fel.cvut.cz \\ ${ }^{+}$Institute of Thermomechanics \\ Academy of Sciences of the Czech Republic \\ Dolejškova 5, 18202 Praha 8, Czech Republic \\ e-mail: valouch@it.cas.cz, skramlik@it.cas.cz
}

\section{Introduction}

Shunt Active Power Filters (APF) are nowadays used for mitigation of harmonic currents from nonlinear loads. Current and voltage harmonics have negative effects on the operation of the electric power system. Thus, great attention is focused on harmonic generation and control. Several standards have introduced limits on current harmonics injected into the power system and on voltage harmonics at the bus-bars of the system.

A conventional measure for the compensation of nonsinusoidal currents and/or lagging power factor of a load, is represented by tuned passive filters (PF) connected in parallel to the load. However, their frequency characteristics are unfavorably influenced by a variable grid impedance and here, in reality, the danger of the excitation of resonance exists. However, the variations of the filter parameters occur due to aging, temperature, and other operations conditions.

The APFs made up of a power converter have been developed to suppress the harmonic currents and improve power factor. The APFs may substitute for passive ones in some cases, or serve as an additional tool, together with PF, for improving the harmonic spectra of the load current and supply voltage. But, the main disadvantage for the use APF in large scale is that complex control and cost of power converter become very high, thus their applications are limited.
Hybrid power filters (HPF) consisting of dedicated passive and active filters connected in series or parallel has been developed. The tolerances and variations in the hybrid filter are not as serious as those in a passive filter used alone. It is also well known that HPF helps to reduce the active filter rating.

Some research efforts have been made to develop new power converters with reduced losses and costs. Among these circuits, the three-phase converter with only two inverter-legs (B4) connection, where one leg is connected directly with centre of the $\mathrm{dc}$ bus voltage, is an alternative solution. Only four power switches and four clamping diodes are used in the adopted converter instead of six power switches and six clamping diodes used in a conventional converter (B6) connection. But, the main disadvantages of four-switch presented topology are as follows:

i) The center of the dc-bus voltage must be accessible, as one of the three converter phases is directly connected with this center point.

ii) The size of the dc-link capacitor must be high to prevent a pulsation of the dc-bus center point as the current going through this point is not dc but it has ac character.

In this paper a new topology introduced in [1] is analytically investigated. The system configuration is shown in Fig.1. The passive device consists of a series inductor and capacitor set, and the voltage source converter (VSC) is a two-leg bridge structure. As can be seen in this configuration, one phase (in our example 
phase "a") of the passive filter is directly connected with any one of the dc terminal of a four-switch converter (in our example minus dc bus terminal). Consequently, the number of power switching devices is reduced and disadvantages i)-ii) are avoided, as the dc-mid bus point is not utilized.

In [7] we investigated four-switch APF space-vector modulated with the four-fold symmetry. In [10] we applied the same the four-fold symmetry to the HPF. This switching symmetry is a different from a six-fold switching symmetry of a classical six-switch inverter. Although many modern power semiconductor devices offer a high degree of reliability, because of unexpected load conditions or erroneous operation a three-phase converter can develop various faults. These faults have been analyzed and remedial strategies suggested in [8], [9]. Following the fault, the three-phase converter is often fed towards a safe stop. But in many applications stopping of the converter is not possible from the point of view of technology requirements. For this situation some solutions have been suggested, commonly leading to the controller reconfiguration. But reconnection from the pre-fault (normal) situation where the converter is controlled with the six-fold symmetry into four-fold (fault) situation may cause over-currents in the mains.

So, we propose in this paper the same switching symmetry (six-fold) as in a normal (B6) inverter for a four-switch converter shown in Fig.1.

The voltage source converter is controlled by the spacevector modulation (SVM) strategy proposed for B4 connection It means that all switching times valid for one sixth of the output period are the same also in the remaining sixths of the output period. For analytical investigation of such a system we used a very new method, mixed p-z approach [4], to analyze the suggested modification of the SVM for the component minimized SVM VSC. First, unsymmetrical voltage space-vectors are decomposed into symmetrical components using Discrete Fourier Transform (DFT), then, for the voltage symmetrical components, the mathematical model makes use of the Laplace and modified Z-transform to predict response of the line currents.

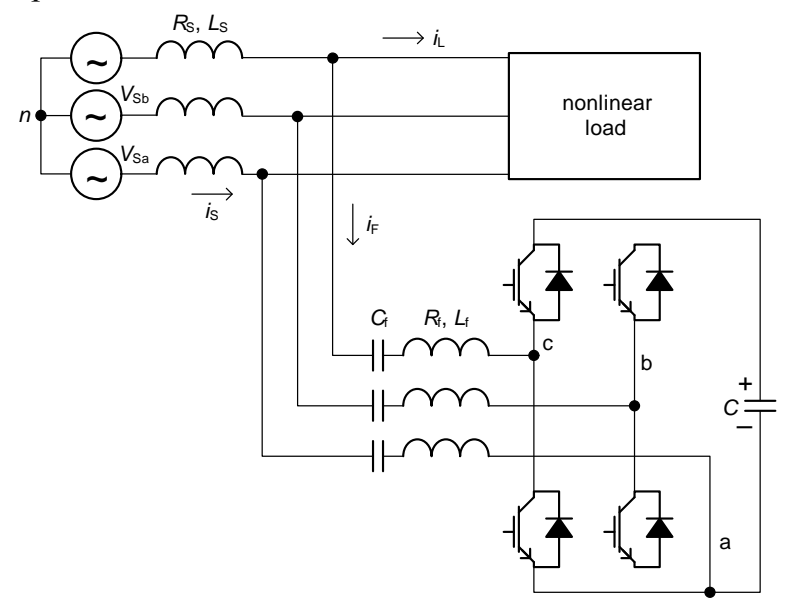

Fig.1 Configuration of the proposed topology

\section{System Configuration}

The system configuration is shown in Fig.1. The passive part of the filter consists of series resistor, inductance and capacitor $\mathrm{R}_{\mathrm{F}}, \mathrm{L}_{\mathrm{F}}$, and $\mathrm{C}_{\mathrm{F}}$, respectively. The voltage-source power converter with only two arms is controlled by the space-vector six-fold pulse width modulation strategy.

\section{Space Vector Modulation for B4 connection with Six-Fold Symmetry}

As in B4 configuration, we have four switching states. We can also find four possible voltage space vectors $\mathbf{V} 1$, $\mathbf{V} 2, \mathbf{V} 3$ and $\mathbf{V} 4$ in the complex $\alpha \beta$ plane as shown in Fig.2. These vectors are $\pi / 2$ away from each other. But, they do not have the same amplitude as in the classical B6 connection. Vectors laying in the real axis have amplitude of $\mathrm{V}_{\mathrm{dc}} / 3$, whereas the vectors lying in the imaginary axis have amplitude of $\sqrt{3} \mathrm{~V}_{\mathrm{dc}} / 3$. As in our new topology the phase " $a$ " is connected with negative dc bus terminal we can use only 4 vectors shown in shade area $(\mathbf{V} 0, \mathbf{V} 3, \mathbf{V} 4$ and $\mathbf{V} 5)$. But, as every phase of the proposed HPF contains a capacitor, which can block the dc-component of the power converter's output, we can see that this space-vector diagram contains a dc offset voltage in every of three phases.

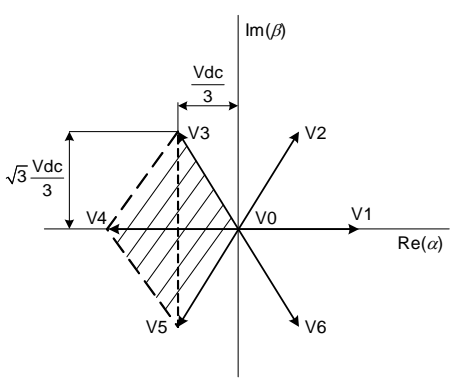

Fig.2 Voltage space-vectors in proposed converter

Let the vectors in Fig.2 have the following denotation

$$
\mathbf{V}_{1}(\mathrm{Z} 00), \mathbf{V}_{2}(\mathrm{Z} 10), \mathbf{V}_{3}(\mathrm{Z} 11), \mathbf{V}_{4}(\mathrm{Z} 01)
$$

where $\left(Z, S_{B}, S_{C}\right)$ in (1) denotes the inverter switching states, in which $\mathrm{S}_{i}=1(i=\mathrm{B}, \mathrm{C})$ if the upper leg switch is on and $\mathrm{S}_{i}=1$ if the upper leg switch is off. $\mathrm{Z}$ means zero pole voltage $\mathrm{V}_{\mathrm{A}}=0$. It means that from the ac utility point of view the voltage space vector diagram in Fig. 2 is shifted by a dc-offset voltage space-vector

$$
\mathrm{V}_{\text {off }}=-\mathrm{V}_{\mathrm{dc}} / 3
$$

As can be seen from Fig.2, the dc-phase components of the capacitors forming the voltage space vector $\mathbf{V}_{\text {off }}$ can be derived as $\mathrm{V}_{\mathrm{fa} 0}=-\mathrm{V}_{\mathrm{dc}} / 3, \mathrm{~V}_{\mathrm{fb} 0}=\mathrm{V}_{\mathrm{fc} 0}=\mathrm{V}_{\mathrm{dc}} / 6$

As it was mentioned earlier for this connection with only four switches we want to have the same switching symmetry as in normal B6 inverter. To form six-fold symmetry we must use some vectors for the whole output 
period twice. Instead of system (1) we can use the system.

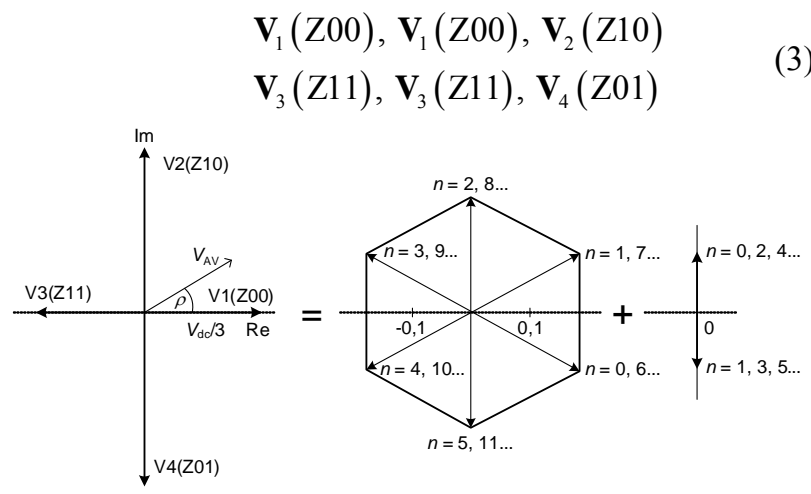

Fig.3 Voltage space vector decomposition

For the next calculations we express time in terms of the sector number $\mathrm{n}$ and per unit time variable $\varepsilon$ as:

$$
\mathrm{t}=(n+\varepsilon) \mathrm{T}_{1} / 6=(n+\varepsilon) \mathrm{T} \quad n=0,1,2, \ldots 0 \leq \varepsilon \geq 1
$$

$\mathrm{T}_{1}$ is a fundamental period, $\mathrm{T}$ is time of periodicity of a space-vector modulation and it is called a sector period

$$
\mathrm{T}=\mathrm{T}_{1} / 6
$$

Using Discrete Fourier Transform (DFT) [2] the unsymmetrical sequence (3) can be decomposed into two symmetrical ones as follows:

$$
\begin{gathered}
\mathrm{V}(n)=\frac{\mathrm{V}_{\mathrm{dc}}}{3} \frac{2}{\sqrt{3}} e^{-\mathrm{j} \pi / 6} e^{\mathrm{j} \pi \frac{n}{3}}+\frac{\mathrm{V}_{\mathrm{dc}}}{3} \frac{1}{\sqrt{3}} e^{\mathrm{j} \pi / 2} e^{\mathrm{j} \pi n}= \\
=\mathrm{V}_{1}(n)+\mathrm{V}_{3}(n)
\end{gathered}
$$

As can be seen from (6) the unsymmetrical vector sequence (3) can be decomposed into two symmetrical ones. The first sequence has symmetry $\pi / 3$ as in the conventional B6 inverter, but its amplitude is lowered by $1 / \sqrt{ } 3$ times and the phase is rotated by $(-\pi / 6)$ as compared with the conventional B6 inverter.

The second symmetrical sequence is laying in the imaginary axis and it has amplitude lowered by two times compared with the first sequence. Because of its period, this sequence will form the third order voltage harmonics in the output cycle period.

Now, we can write (see in Fig.1) for space-vector notation in the Laplace transform

$$
\begin{gathered}
\mathbf{v}_{\mathrm{S}}(p)=\left(\mathrm{R}_{\mathrm{S}}+p \mathrm{~L}_{\mathrm{S}}\right) \mathbf{i}_{\mathrm{S}}(p)+ \\
+\left(\mathrm{R}_{\mathrm{F}}+p \mathrm{~L}_{\mathrm{F}}+1 / p \mathrm{C}_{\mathrm{F}}\right) \mathbf{i}_{\mathrm{F}}(p)+\mathbf{v}^{*}(p) \\
\mathbf{i}_{\mathrm{S}}(p)=\mathbf{i}_{\mathrm{L}}(p)+\mathbf{i}_{\mathrm{F}}(p)
\end{gathered}
$$

where $\mathbf{v}^{*}(p)$ is the Laplace transform of the VSC output voltage. This voltage can be found using the modified Ztransform in the following form [4]

$$
\begin{gathered}
\mathbf{v}^{*}=\mathrm{V}_{1}(p)+\mathrm{V}_{3}(p)= \\
=\frac{1}{p} \frac{2 \mathrm{~V}}{3 \sqrt{3}}\left[\frac{e^{p \mathrm{~T}} e^{-\mathrm{j} \pi / 6}}{e^{p \mathrm{~T}}-e^{-\mathrm{j} \pi / 3}} \sum_{\mathrm{k}=1}^{\mathrm{M}} e^{\mathrm{j} \pi \alpha(k) / 3}\left(e^{-p \mathrm{~T} \varepsilon_{k A}}-e^{-p \mathrm{~T} \varepsilon_{k B}}\right)\right]+ \\
+\frac{1}{p} \frac{\mathrm{V}}{3 \sqrt{3}}\left[\frac{e^{p \mathrm{~T}} e^{\mathrm{j} \pi / 2}}{e^{p \mathrm{~T}}-e^{\mathrm{j} \pi}} \sum_{\mathrm{k}=1}^{\mathrm{M}} e^{\mathrm{j} \pi \alpha(k)}\left(e^{-p \mathrm{~T} \varepsilon_{k A}}-e^{-p \mathrm{~T} \varepsilon_{k \mathrm{~B}}}\right)\right]
\end{gathered}
$$

where $\varepsilon_{\mathrm{kA}}, \varepsilon_{\mathrm{kB}}$ are respectively, the beginning and the end of the application of $\mathrm{k}$-th voltage space-vector inside of a sector period. These times are given by switching SVM strategy. The modulation strategy proposed has the same symmetry as for the B6 inverter and is simple without significant increase in switching frequency. The proposed modulation strategy is realized by planning the switching patterns between four active voltage vectors within a sampling period:

a) Utilizing the first voltage vector sequence term $\mathbf{V}_{1}(n)$ in (6). As in a usual space vector modulation (SVM), four consecutive voltage vectors in a sampling period are used to generate the average output voltage matching with the reference voltage.

b) Minimizing the second voltage vector sequence term $\mathrm{V}_{3}(n)$ in (6). For minimization, the average voltage from the $\mathbf{V}_{3}(n)$ within a sampling period should be zero.

For calculation of the switching times we need to know the modulation factor $g$ and a polar angle $\rho$ of the reference voltage $\mathbf{V}_{\mathrm{AV}}$ to the real axis. But these are not constants as in the classical SVM but they are calculated as follows.

For the steady state we can write (for zero power factor) for VSC terminal voltage

$$
\begin{gathered}
\mathbf{V}_{\mathrm{S}}=\mathrm{V}_{\mathrm{S}} e^{\mathrm{j} \omega_{1}(n+\varepsilon) \mathrm{T}} \\
\mathbf{I}_{\mathrm{S}}=\mathrm{I}_{\mathrm{S}} e^{\mathrm{j} \omega_{1}(n+\varepsilon) \mathrm{T}} \\
\mathrm{v}^{*}=\mathrm{V}_{\mathrm{S}}-\mathrm{I}_{\mathrm{S}}\left(\mathrm{Z}_{\mathrm{S}}+\mathrm{Z}_{\mathrm{F}}\right)+\mathrm{Z}_{\mathrm{F}} \mathrm{I}_{\mathrm{F}}=g(\varepsilon) e^{\mathrm{j} p(\varepsilon)}
\end{gathered}
$$

As a nonlinear load we assume the full bridge rectifier. This load current space vector can be expressed as

$$
\mathrm{i}_{\mathrm{L} 11}(n, \varepsilon)=\frac{2}{\sqrt{3}} \mathrm{I}_{\mathrm{d}} e^{\mathrm{j} \pi / 2} e^{\mathrm{j} \pi(n-1) / 3}
$$

with the phase load current given by a real part of (10) and shown in Fig.4.

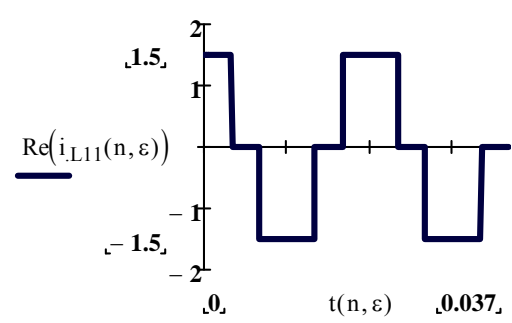

Fig.4 Nonlinear load current 
Now, we can calculate from (5) the utility current $\mathrm{i}_{\mathrm{S}}(n, \varepsilon)$. This current can be determined using mixed $\mathrm{p}-\mathrm{z}$ approach in analytical closed-form. The expressions for this current both in the Laplace and time domains are given as follows:

In Laplace domain

$$
\begin{gathered}
\mathrm{I}_{\mathrm{S}}(p)=\frac{1}{\mathrm{Z}_{\mathrm{S}}(p)+\mathrm{Z}_{\mathrm{F}}(p)} . \\
\cdot\left(\mathrm{V}_{\mathrm{S}}(p)+\mathrm{Z}_{\mathrm{F}}(p) \mathrm{I}_{\mathrm{L}}(p)-\mathrm{v}(p)\right)
\end{gathered}
$$

In time domain

$$
\begin{gathered}
\mathrm{i}_{\mathrm{S}}(n, \varepsilon)=\mathrm{L}^{-1}\left\langle\mathrm{I}_{\mathrm{S}}(p)\right\rangle= \\
=\mathrm{i}_{1}(n, \varepsilon)+\mathrm{i}_{\mathrm{L} 6}(n, \varepsilon)+\mathrm{i}_{\mathrm{ST}}(n, \varepsilon)
\end{gathered}
$$

where $\mathrm{L}^{-1}$ means the inverse Laplace transform. But this step must be done by means of the mixed $\mathrm{p}-\mathrm{z}$ approach as demonstrated in [4].

The utility current contains three fictitious currents $\mathrm{i}_{1}(n, \varepsilon)+\mathrm{i}_{\mathrm{L} 6}(n, \varepsilon)+\mathrm{i}_{\mathrm{ST}}(n, \varepsilon)$ :

- $\mathrm{i}_{1}(n, \varepsilon)$ is a fictitious current from the supply voltage $\mathrm{V}_{\mathrm{S}}$,

- $\quad \mathrm{i}_{\mathrm{L} 6}(n, \varepsilon)$ is a second fictitious current given by the voltage $\mathrm{Z}_{\mathrm{F}} \mathrm{I}_{\mathrm{L}}$ and

- $\mathrm{i}_{\mathrm{ST}}(n, \varepsilon)$ is a third fictitious current given by a voltage of a four-switch converter $\mathrm{v}$.

The trajectories of these currents in complex $\alpha \beta$ plane are shown in Fig.5 a), b), c) for the following parameters: $\mathrm{V}_{\mathrm{S}}=120 \sqrt{2} \mathrm{~V}, \mathrm{~V}_{\mathrm{dc}}=700 \mathrm{~V}, \mathrm{I}_{\mathrm{S}}=1.5 \mathrm{~A}, \mathrm{R}_{\mathrm{S}}=1.0 \Omega$,

$\mathrm{L}_{\mathrm{S}}=0.1 \mathrm{H}, \mathrm{R}_{\mathrm{F}}=2.0 \Omega, \mathrm{L}_{\mathrm{F}}=0.005 \mathrm{H}$,

$\mathrm{C}_{\mathrm{F}}=0.000041 \mathrm{~F}$

In Fig. 6 we can see trajectories of the utility overall current and also phase current waveforms

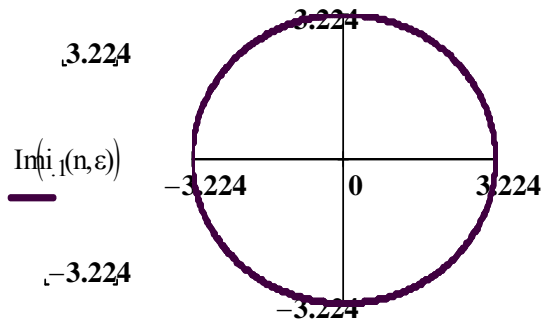

-3.22,4 Rei. $(\mathrm{n}, \varepsilon)) \quad 3.224$

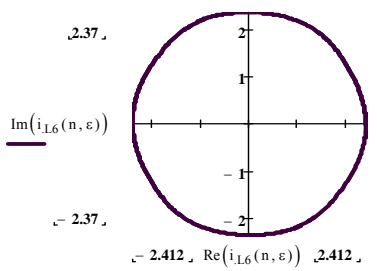

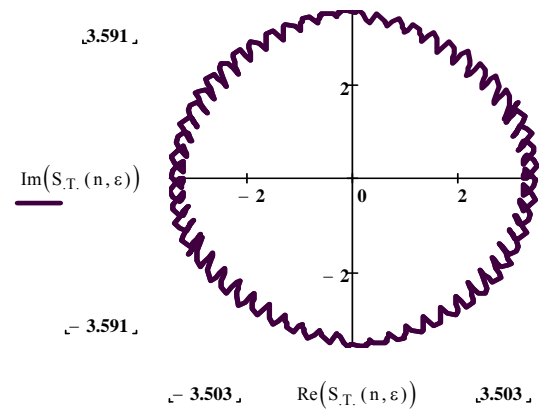

Fig.5 Trajectories of three fictitious current forming overall utility current $i_{1}$ (top), $i_{\mathrm{L} 6}$ (middle), $i_{\mathrm{ST}}$ (bottom)
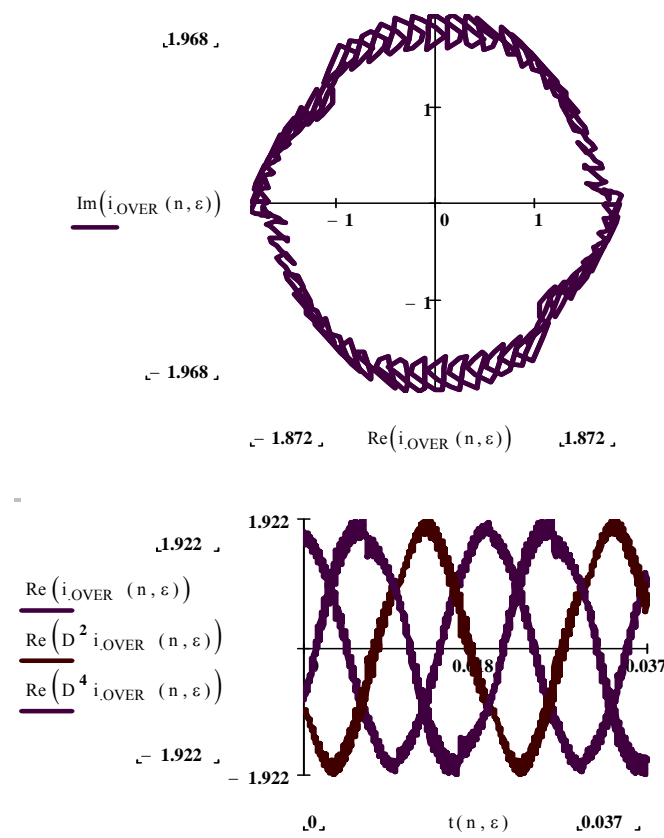

Fig.6 Utility space-vector current (top) and phase waveforms (bottom)

In Fig.7 we can see the HPF current. All these results were calculated by using the closed-form equations and visualized by the program MATHCAD.

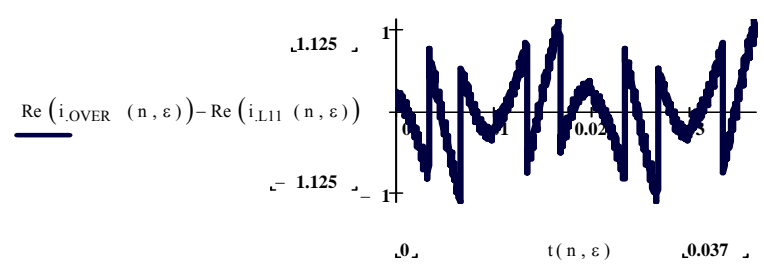

Fig.7 HPF current

\section{Experimental results}

We verified the proposed method through experiments. The experimental system consists of a three-phase inverter, $\mathrm{R}_{\mathrm{f}}, \mathrm{L}_{\mathrm{f}}$, and $\mathrm{C}_{\mathrm{f}}$ passive filter (tuned to the $7^{\text {th }}$ harmonic) and a nonlinear load (a three-phase uncontrolled rectifier). The setup contains also digital control unit. The inverter is an integrated power module 
MITSUBISHI PS12038 (1200 V, $25 \mathrm{~A}, 15 \mathrm{kHz}$ at maximum). The digital control unit, based on the dSPACE control system DS 1103, generates firing signals for the PWM rectifier. The parameters of the experimental setup are given in Table 1.

Table 1

\begin{tabular}{|l|l|l|l|}
\hline Grid & $R_{\mathrm{S}}=1.4 \Omega$ & $L_{\mathrm{S}}=11.1 \mathrm{mH}$ & \\
\hline $\begin{array}{l}\text { Passive } \\
\text { filter }\end{array}$ & $R_{\mathrm{f}}=1 \Omega$ & $L_{\mathrm{f}}=5 \mathrm{mH}$ & $C_{\mathrm{f}}=41 \mu \mathrm{F}$ \\
\hline $\begin{array}{l}\text { Active } \\
\text { power filter }\end{array}$ & $T_{\mathrm{S}}=250 \mu \mathrm{S}$ & $f_{\mathrm{SW}}=4 \mathrm{kHz}$ & $t_{\text {dead }}=1 \mu \mathrm{S}$ \\
\hline & $C_{\mathrm{dc}}=832 \mu \mathrm{F}$ & $v_{\mathrm{dc}}=286 \mathrm{~V}$ & \\
\hline $\begin{array}{l}\text { HP signal } \\
\text { filter }\end{array}$ & $f_{\mathrm{c}}=16 \mathrm{~Hz}$ & $1^{\text {st }}$ order & $\begin{array}{l}\text { for detection } \\
\text { of harmonic } \\
\text { currents }\end{array}$ \\
\hline
\end{tabular}

Fig. 8 shows the proposed control scheme of the HPF. A harmonic current detective control is applied where source phase currents are transformed into two orthogonal components in the reference frame rotating with the synchronous angular speed $\omega_{1}$. By using a high pass filter $(\mathrm{HpF})$ of the first order with the cut-off frequency $f_{\mathrm{c}}=2 \mathrm{~Hz}$ fluctuating $d q_{1}$ components of the source current are obtained. These components should be compensated for by using the HPF. Thus, three reference phase currents of the HPF may be obtained by applying the reverse transformation.

In order to control the magnitude of the DC voltage $u_{\mathrm{dc}}$, an additional control loop is inserted into the $q_{1}$ axis path in the feedback control part. Also into the $d_{1}$ axis part another control loop is inserted, whose aim is to adjust the non-active power delivered from the source to its demanded value. In the control loop an instantaneous non-active power $q_{\mathrm{S}}$ is calculated and by passing it through the low pass filter (LpF) with the cut-off frequency $f_{\mathrm{c}}=16 \mathrm{~Hz}$ an average $\mathrm{DC}$ component is obtained. By comparing it with the reference of the reactive power of the source a control error is got that, after processing in an I-type controller, may represent an additional signal for determining the reference $d_{1}$ component of the compensating APF current $i_{\mathrm{Sd}}^{*}$. The reference $d q_{1}$ compensating APF current components $i_{\mathrm{Sd}}^{*}$, $i_{\mathrm{Sq}}^{*}$ are then transformed back into the phase reference quantities and multiplied by a feedback control gain.

Fig. 9 shows the trajectories of load and utility phase currents. The control loop of the non-active power has not been activated here, so a phase shift between the load and source current is seen due to the capacitor of the passive part of the HPF.

Fig.10 presents the trajectories of load and utility phase currents (top), harmonic spectrum of load current (middle) and utility current (bottom). It is evident that the $5^{\text {th }}, 11^{\text {th }}$, and $13^{\text {th }}$ current harmonics are suppressed approximately three times, but the $7^{\text {th }}$ harmonics is lowered roughly six times, because the passive part of the $\mathrm{HPH}$ is tuned to the $7^{\text {th }}$ harmonic $(350 \mathrm{~Hz})$.

Fig 11 shows the phasor diagrams of the source phase voltages and currents. We see here that the power factor is 0.96 capacitive and the current system is very balanced thanks to the proposed space-vector six-fold pulse width modulation strategy regardless the B4 VSC connection.

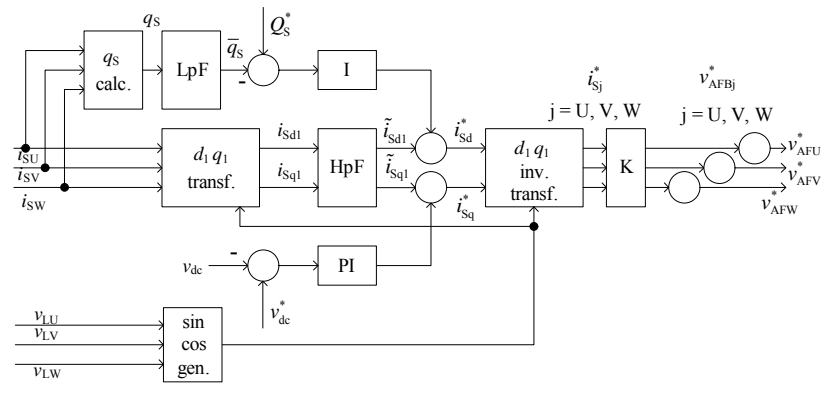

Fig.8 Control strategy of HPH

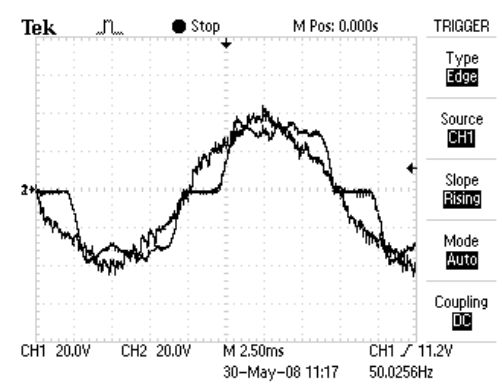

Fig.9 Trajectories of load and utility phase currents (1A/div)
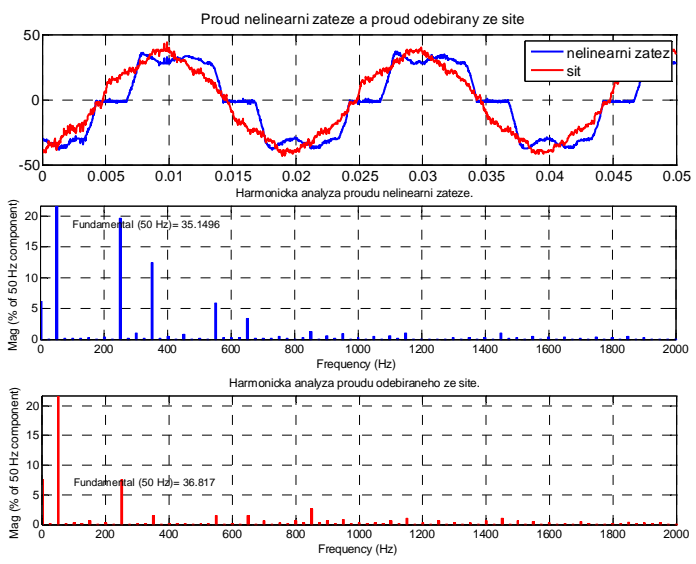

Fig.10 Trajectories of load and utility phase currents (top), harmonic spectrum of load current (middle) and utility current (bottom)

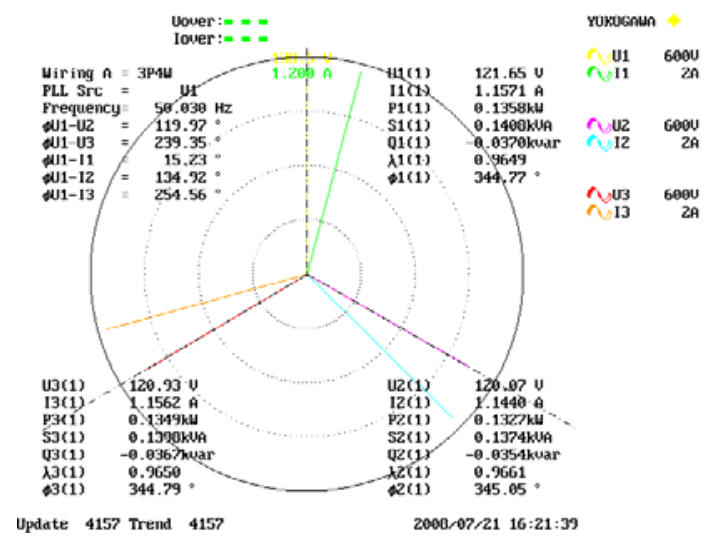

Fig.11 Phasors of source phase voltages and currents 


\section{Conclusion}

In this paper we proposed the analytical model and the original space-vector modulation strategy for a new circuit configuration of a hybrid power filter with only four switches and not utilizing the center point of the dc bus voltage. This configuration removes the problems with pulsation of the dc bus voltage known from the bus clamped converters. Based on the control algorithm, sinusoidal line currents with the non-linear load currents are achieved by the adopted converter. Finally, an original closed-form solution of steady-state line currents, based on the mixed $\mathrm{p}-\mathrm{z}$ approach is introduced. The analytical results and experiment tests on the component minimized three-phase PWM HPF are shown as well to demonstrate the validity and effectiveness of the proposed control scheme.

\section{Acknowledgement}

The financial supports of the Grant Agency of the Academy of Sciences of the Czech Republic (project No. IAA200760703), Institutional Research Plan Z20570509 of the Institute of Thermomechanics of the ASCR, v.v.i., and of the Ministry of Education, Youth and Sports (Research Plan MSM 6840770017 of the Czech Technical University) are highly acknowledged.

\section{References}

[1] Wu J. Jou, H. Feng, Y. Hsu, W. Huang, W. Hou, "Novel Circuit Topology for Three-Phase Active Power Filter". IEEE Transactions on PD-22, No. 1, 2007, pp. 44-449.
[2] J. Klima, "Analytical closed-form solution of a spacevector modulated VSI feeding an induction motor drive," IEEE Transaction on Energy Corversion, Vol. 17, No. 2, pp. 191-196, June 2002.

[3] J. Škramlík, V. Valouch, "Coupled Feedforward and Feedback Control Strategy of Parallel Hybrid Filter for Harmonic Mitigation," Inter. Conference on Renewable Energies and Power Quality - ICREPQ 05, Zaragoza, Spain, March 16-18, pp. 1-3, 2005.

[4] J. Klima, "Mixed p-z approach for time-domain analysis of voltage source inverters with periodic pulse width modulation." IEEE Transactions on Circuits and Systems II. 2004, No. 10, October, pp. 529-536.

[5] B. R. Lin, T. C. Wei, „Analysis and implementation of a three-phase two-leg neutral point clamped converter based on space vector PWM for power factor correction". IEE Proceedings-Electric Power Applications, Vol. 151, No. 1, pp. 38-46, Jan. 2004.

[6] J. Klima, "Analytical closed-form solution of a spacevector modulated VSI feeding an induction motor drive," IEEE Transaction on Energy Corversion, Vol. 17, No. 2, pp. 191-196, June 2002.

[7] J. Klima, J. Skramlik, V. Valouch, „An Analytical Modelling of Three-Phase Four-Switch PWM Rectifier Under Unbalanced Supply Conditions,“ IEEE Trans. on Circuits and System II, 2007, No. 6, pp. 1155-1159.

[8] C. Cecati, N. Rotondale, "A double PWM-strategy for improved electric drive reliability. Proceedings of Conf.Speedam,“ 2002, pp. A2-25-A2-30.

[9] D. Kastha, B. K. Bose, "Investigation of fault modes of voltage-fed inverter system for induction motor drive," IEEE Trans. Ind. Appl. Vol. 30, 1994, pp. 259-266.

[10] J. Klima, J. Skramlik, V. Valouch, "Analytical modeling and implementation of a new four-swirch hybrid power filter topology" Inter. Conference on Renewable Energies and Power Quality - ICREPQ 08, Santander, Spain, March 12-14, CD-ROM, ISBN: 978-84-611-9290-8. 